\title{
Studying the Properties of RF-Sputtered Nanocrystalline Tin-Doped Indium Oxide
}

\author{
Abd El-Hady B. Kashyout, ${ }^{1}$ Marwa Fathy, ${ }^{1}$ and Moataz B. Soliman² \\ ${ }^{1}$ Advanced Technology and New Materials Research Institute, Mubarak City for Scientific Research and Technology Applications, \\ New Borg El-Arab City, Alexandria 21934, Egypt \\ ${ }^{2}$ Institute of Graduate Studies and Research, Alexandria University, 163 Horrya Avenue, P.O. Box 832, Shatby, \\ Alexandria 21526, Egypt \\ Correspondence should be addressed to Abd El-Hady B. Kashyout, hady8@yahoo.com
}

Received 27 January 2011; Revised 28 February 2011; Accepted 31 March 2011

Academic Editor: Mohamed Sabry Abdel-Mottaleb

Copyright (C) 2011 Abd El-Hady B. Kashyout et al. This is an open access article distributed under the Creative Commons Attribution License, which permits unrestricted use, distribution, and reproduction in any medium, provided the original work is properly cited.

\begin{abstract}
The ceramic target of Indium tinoxide (ITO) $\left(90 \% \mathrm{In}_{2} \mathrm{O}_{3}-10 \% \mathrm{SnO}_{2}\right)$ has been used to prepare transparent semiconductive thin films on glass substrate by RF magnetron sputtering at room temperature. The properties of the thin films are affected by controlling the deposition parameters, namely, RF power values and deposition times. The structure, morphology, optical and electrical properties of the thin films are investigated using X-ray diffraction (XRD), field emission scanning electron microscope (FESEM), atomic force microscope (AFM), UV-Vis spectrophotometer, and four-point probe measurement. Nanoparticles of 10 $20 \mathrm{~nm}$ are measured and confirmed using both FESEM and AFM. The main preferred orientations of the prepared thin films are (222) and (400) of the cubic ITO structure. The transparent semiconductive films have high transmittance within the visible range of values $80-90 \%$ and resistivity of about $1.62 \times 10^{-4} \Omega \cdot \mathrm{cm}$.
\end{abstract}

\section{Introduction}

Indium-tin-oxide (ITO) thin film is n-type degenerated semiconductor with a wide band gap $(\mathrm{Eg} \sim 3.3 \mathrm{eV})[1]$. It has high photoelectrolytic properties: high transparence in the range of visible spectrum ( $>95 \%)$, high reflectance in the infrared (IR) range ( $>80 \%$ ) because of its high density of free electrons in ITO conduction band, and high conductivity $\left(10^{-4} \Omega \cdot \mathrm{cm}\right)$ similar to a metallic material [1]. It is usually deposited at temperature above $200^{\circ} \mathrm{C}$, since it is difficult to obtain a thin film with a resistivity below $2 \times 10^{-4} \Omega \cdot \mathrm{cm}$ at a low substrate temperature. However, low-temperature deposition, below $100^{\circ} \mathrm{C}$, is necessary to deposit films on plastic substrates that have poor heat resistance, such as polycarbonate [2] polyethylene terephthalate [3] and polyethersulfone [4]. ITO coatings are the most widely used as transparent conductive oxide (TCO) coatings in various applications such as transparent conducting electrode in flatpanel displays (FPDs) [5], organic light emitting diodes (OLEDs) [6], and photovoltaic solar cells because they have high electrical conductivity, high optical transparency, and smooth surface morphology [7-10].

ITO thin films are prepared using various methods such as DC, pulsed DC, and RF magnetron sputtering [11-13], reactive evaporation [14], ion beam assisted deposition [15], sol-gel, co-precipitation $[16,17]$, chemical vapor deposition (CVD) [18], and spray pyrolysis [19]. Magnetron sputtering is one of the most versatile techniques for ITO thin films preparation. This technique provides a uniform fabrication of the reproduction of ITO thin films, which is advantageous for many applications in industry [20].

The optical and electrical properties of ITO coatings are sensitive to process parameters and depend on the control of films composition, structure, crystallinity, defect density, surface roughness, and dopant concentration [21, 22].

In this paper, the crystallization behavior of ITO thin films deposited at room temperature under Ar atmosphere by RF magnetron sputtering is examined as a function of RF power values and deposition time, aiming to determine the conditions that lead to the production of thin films with 
an optical band gap $(3.5 \mathrm{eV})$ and transparency $(\geq 90 \%)$ in the visible region and in some cases near IR region. Also, low resistivity, good surface uniformity, highly smooth and chemically stable surfaces in various environments are essential parameters that should be investigated.

\section{Experimental Details}

The ITO thin films were deposited on $1 \mathrm{~mm}$ thick soda lime glass by RF magnetron sputtering technique using the system (HUMMER 8.1) under an $\mathrm{Ar}$ atmosphere. $\mathrm{SnO}_{2}-\mathrm{In}_{2} \mathrm{O}_{3}$ sintered disks of $10 \mathrm{~cm}$ in diameter were used as the target. Glass was precleaned with ethanol and acetone, respectively. The chamber was evacuated to a background pressure of 0.6 mTorr initially, and the working pressure during the film deposition was fixed to 7-10 mTorr by utilizing pure Ar (99.999\%) gas. The RF power varied from 50 to $300 \mathrm{~W}$, whereas the deposition time varied from 10 to $40 \mathrm{~min}$. The deposition process is carried out at room temperature, that is, the substrate is not heated during the film deposition.

The film crystalline structure was investigated by Xray diffractometer (Schimadzu-7000) using $\mathrm{Cu}-\mathrm{K} \alpha$ radiation target. The optical transmittance was measured using a UV-Vis double beam spectrophotometer (Ultrospec 2000Pharmacia Biotech Co.) in the wavelength range from $200 \mathrm{~nm}$ to $1100 \mathrm{~nm}$. The surface morphology of the films was observed with a field emission scanning electron microscope (JEOL 7600) and the average surface roughness is measured under ambient conditions with an atomic force microscope (AFM) JEOL-JSPM-5400 in the noncontact mode. The resistivity of the coatings is measured using a four-point probe technique (Sigma One) and the reported value was an average of three measurements over the sample.

\section{Results and Discussion}

3.1. Structural Properties. Figure 1 shows the X-ray diffraction patterns of the ITO thin films deposited with various $\mathrm{RF}$ power values at a constant working pressure, and the deposition time is fixed at $40 \mathrm{~min}$. At low deposition power of $50 \mathrm{~W}$ (Figure $1(\mathrm{a})$ ), the ITO thin film shows no diffraction peaks, which may indicate amorphous state of the deposited film. Increasing the deposition power to $100 \mathrm{~W}$ (Figure 1(b)), the deposited film shows the appearance of the (222) peak of the ITO cubic structure (JCPDS Card No. 06-0416).

Starting from a deposition power of $150 \mathrm{~W}$, most of the typical ITO diffraction peaks of (222), (400), (440), and (622) are detected as shown in Figure 1(c). It has been observed that the (222) preferential orientation is highly dominant at the initial growth stage for any deposition condition. This is due to the fact that during the nucleation stage of ITO thin films, indium atoms on substrate are likely to aggregate into densely packed (111) planes which are close to (222) planes in the bixbyite structure. But the dominant nature changed from (222) to (400) when there is an increase in substrate temperature and also due to an increase in film thickness due to increasing the power value [23].

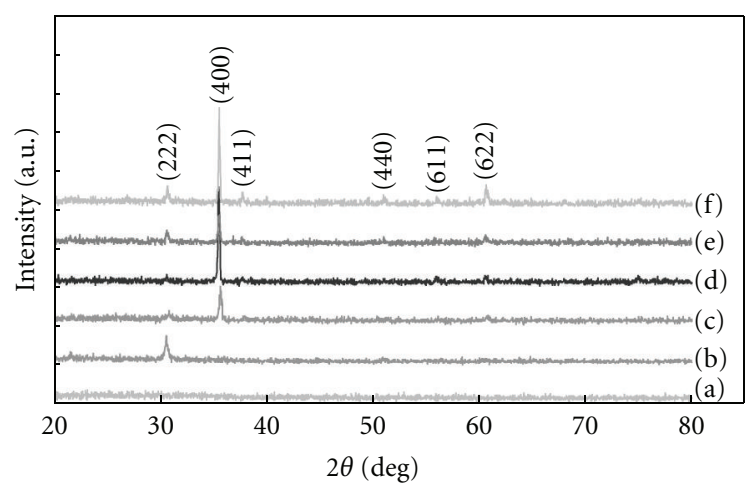

FIGURE 1: XRD patterns for ITO thin films deposited for $40 \mathrm{~min}$ deposition using various RF power, (a) 50, (b) 100, (c) 150, (d) 200, (e) 250 and (f) $300 \mathrm{~W}$.

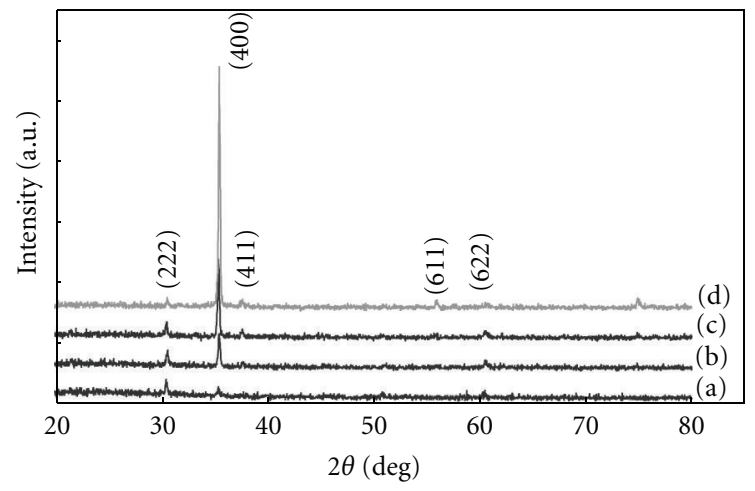

FIgURE 2: XRD patterns for ITO thin films deposited using RF power value of $200 \mathrm{~W}$ and various deposition time, (a) 10, (b) 20, (c) 30 and (d) 40 min.

A preferential orientation of (400) plane is observed as the deposition power is increased from 150 to $300 \mathrm{~W}$ as shown in Figure 1 ((c)-(f)). The data also shows that the peak position slightly shifts to a lower $2 \theta$ value as the power increases while the full width half maximum (FWHM) decreases, meaning that the film grain size increases [4]. It has also been noted that the intensity of the (222) diffraction peak does not increase significantly any more when the thickness is higher than a certain value, whereas the (400) diffraction intensity increases for thicker films. Thus, the growth of the (222) grains is suppressed when the thickness increases [24]. According to the literature, the predominant orientation changes from (222) to (400) as the oxygen incorporation in the structure decreases or as the deposition rate increases which is in good agreement with the presented results. On the other hand, the change in the orientation from (222) to (400) can also be influenced by the deposition rate because the (222-) oriented grains are less resistant against sputtering than the (400-) oriented grains [24].

Figure 2 shows the XRD patterns of the grown ITO thin films at a constant power of $200 \mathrm{~W}$ and various deposition times. The film deposited for $10 \mathrm{~min}$ (Figure 2(a)) reveals low-diffraction intensities of the ITO crystal structure (JCPDS Card No. 06-0416) with the preferred orientation of 


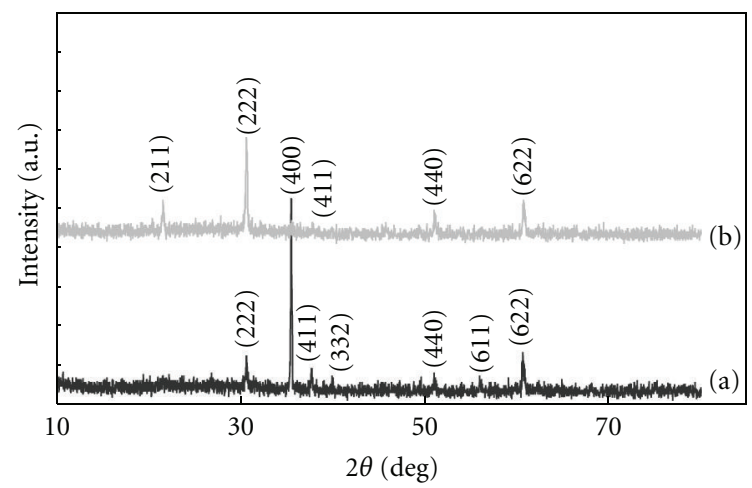

FIgURE 3: XRD patterns for ITO thin films deposited using RF power value $200 \mathrm{~W}$ for 40 min deposition time: (a) without, (b) with heat treatment at $400^{\circ} \mathrm{C}$ for $1 \mathrm{~h}$.

the (222) plane, and changing the orientation to (400) plane will increase the deposition time to 20,30 , and $40 \mathrm{~min}$ (Figure $2((\mathrm{~b}),(\mathrm{c})$, and $(\mathrm{d})))$. It is known that the thickness of the deposited film affects the X-ray spectra [24]. Thin crystallized film deposited for 10 min might represent the diffraction peak with very low intensity.

During deposition, plasma provides the sample with heat that increases temperature to about $150^{\circ} \mathrm{C}$. This temperature is required in order to have a crystalline structure $[6,14,15]$. One aspect of the plasma-surface interactions is the transfer of energy. Energy transfer from plasma to solid surfaces occurs through optical radiation and fluxes of neutral particles and ions. In plasma, at a pressure below $1 \mathrm{~Pa}$ (7.5 mTorr), the degree of ionization is very high, the density of neutrals is much lower than that of ions, and the ions collisions are predominant [16]. During the ion bombardment, the dissipation of the kinetics and the vibration energy fractions of ions causes heating of the substrate [16]. Therefore, a deposition time up to $40 \mathrm{~min}$ resulted in good crystallization by the prolonged energetic bombardment, while insufficient energy for crystallization is transferred to the films when the deposition time is short [17].

Figure 3 illustrates the XRD patterns of the ITO-deposited thin films at a constant power $(200 \mathrm{~W})$ where the effect of heat treatment at $400^{\circ} \mathrm{C}$ for $1 \mathrm{hr}$ is discussed. The nonheated film (Figure 3(a)) shows that the (400) plane is the preferred orientation which may indicate that the oxygen vacancies on these planes are accommodated. On the other hand, the postannealed ITO film (Figure 3(b)) shows that the (222) plane is a preferred one which is a close-packed plane in $\mathrm{In}_{2} \mathrm{O}_{3}$ body-centered cubic structure. This plane does not accommodate oxygen vacancies very well, and so it is stabilized [25].

Also, heat treatment causes a decrease in lattice constant (a) which is calculated using (1)

$$
d_{\mathrm{hkl}}=\frac{a}{\sqrt{h^{2}+k^{2}+l^{2}}}
$$

where $d$ is the spacing between adjacent (hkl) lattice planes. It is decreased from $1.023 \mathrm{~nm}$ to $1.011 \mathrm{~nm}$ due to the attractive

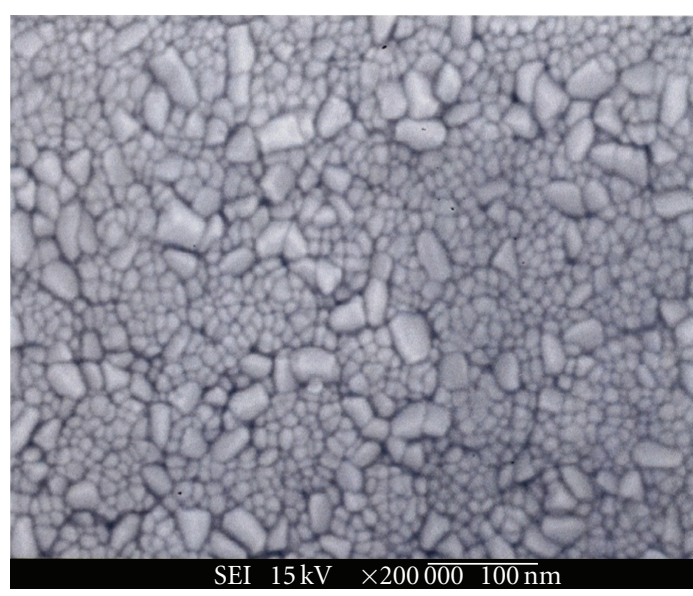

FIGURE 4: FESEM for ITO thin films deposited using RF power value of $200 \mathrm{~W}$ for $40 \mathrm{~min}$ deposition time.

force between the metal ions and the extra interstitial oxygen ions [26].

3.2. Morphological Properties. The FESEM and AFM of ITO thin films are shown in Figures 4 and 5, respectively, to show the film morphology and roughness. Figure 4 shows that the average grain size is about $10 \mathrm{~nm}$ with high density accompanied by large grains of $20-30 \mathrm{~nm}$ with low density is observed and may be explained as: for the thick film, a change from (222) to (400) orientation and columnar grains growing perpendicular to the substrate by increasing the deposition time to $40 \mathrm{~min}$. It was previously reported that the morphology and orientation of ITO films depend on the energy of particles arriving to the substrate have been found.

Figure 5 shows the topography of the ITO thin film deposited at room temperature for $40 \mathrm{~min}$. The average film roughness value calculated from this image is about $20 \mathrm{~nm}$. According to the literature $[27,28]$, the average roughness increases with increasing the film thickness. In the same way, it has been reported for ITO films prepared by various techniques $[29,30]$ that the grain size enlargement is related with the increase of the film thickness.

3.3. Optical Properties. Several methods have been used to determine the optical constants of thin films based on the measurement of the intensity of the reflected, absorbed and/or transmitted light as a function of wavelength and/or the angle of incidence. Among these methods, the one given by Swanepoel is widely used because it is a simple method and does not need a complicated computer program [31].

$T_{M}$ and $T_{m}$, which are the maximum and the minimum of the transmittance of the envelope of interference, are now considered to be continuous functions of $\lambda$. For any $\lambda, T_{M}$ has a correspondent $T_{m}$ value: The refractive index is calculated by Manifacier et al. [32]

$$
n=\left[N+\left(N^{2}-S^{2}\right)^{1 / 2}\right]^{1 / 2},
$$




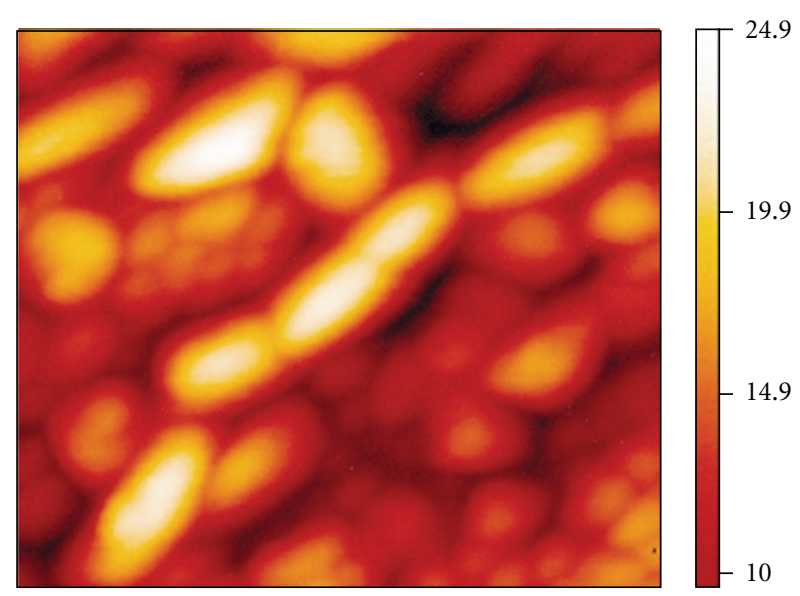

FIGURE 5: AFM for ITO thin films deposited using RF power value of $200 \mathrm{~W}$ for $40 \mathrm{~min}$ deposition time.

TABLE 1: Resistivity, thickness and refractive index of ITO thin films deposited using various RF power for 40 min deposition time.

\begin{tabular}{lccc}
\hline $\begin{array}{l}\text { RF power } \\
(\mathrm{W})\end{array}$ & $\begin{array}{c}\text { Thickness } \\
(\mu \mathrm{m})\end{array}$ & $\begin{array}{c}\text { Refractive } \\
\text { index }\end{array}$ & $\begin{array}{c}\text { Resistivity } \\
(\Omega \cdot \mathrm{cm})\end{array}$ \\
\hline 50 & 0.50 & 1.48 & $77.15 \times 10^{-4}$ \\
100 & 0.59 & 1.49 & $9.98 \times 10^{-4}$ \\
150 & 0.63 & 1.5 & $3.96 \times 10^{-4}$ \\
200 & 1.09 & 1.506 & $1.62 \times 10^{-4}$ \\
250 & 1.17 & 1.505 & $2.32 \times 10^{-4}$ \\
300 & 1.29 & 1.509 & $2.38 \times 10^{-4}$ \\
\hline
\end{tabular}

where $N$ is defined as

$$
N=\frac{2 S\left(T_{M}-T_{m}\right)}{T_{M} T_{m}}+\frac{\left(S^{2}+1\right)}{2},
$$

where $S$ is the refractive index of the glass substrate.

If $n_{1}$ and $n_{2}$ are the refractive indices at two adjacent maxima (or minima) at $\lambda_{1}$ and $\lambda_{2}$, according to the basic equation of interference fringes,

$$
2 n t=m \lambda,
$$

the thickness $t$ of the film is given by

$$
t=\frac{\lambda_{1} \lambda_{2}}{2\left(\lambda_{1} n_{2}-\lambda_{2} n_{1}\right)} .
$$

Table 1 shows an example of the calculated refractive indices and thicknesses of the ITO samples prepared with different RF power. With increasing the power value, the refractive index and the thickness are increased from 1.48 and. $5 \mu \mathrm{m}$ (power value $=50 \mathrm{~W}$ ) to 1.509 and $1.29 \mu \mathrm{m}$ (power value $=300 \mathrm{~W}$ ), respectively, with increasing the deposition time, the refractive index and the thickness are increased from 1.499 and. $46 \mu \mathrm{m}$ (deposition time $=10 \mathrm{~min}$ ) to 1.506 and $1.09 \mu \mathrm{m}$ (deposition time $=40 \mathrm{~min}$ ), respectively.

The measured optical transmittance as a function of the light wavelength is represented in Figures 6 and 7 for ITO

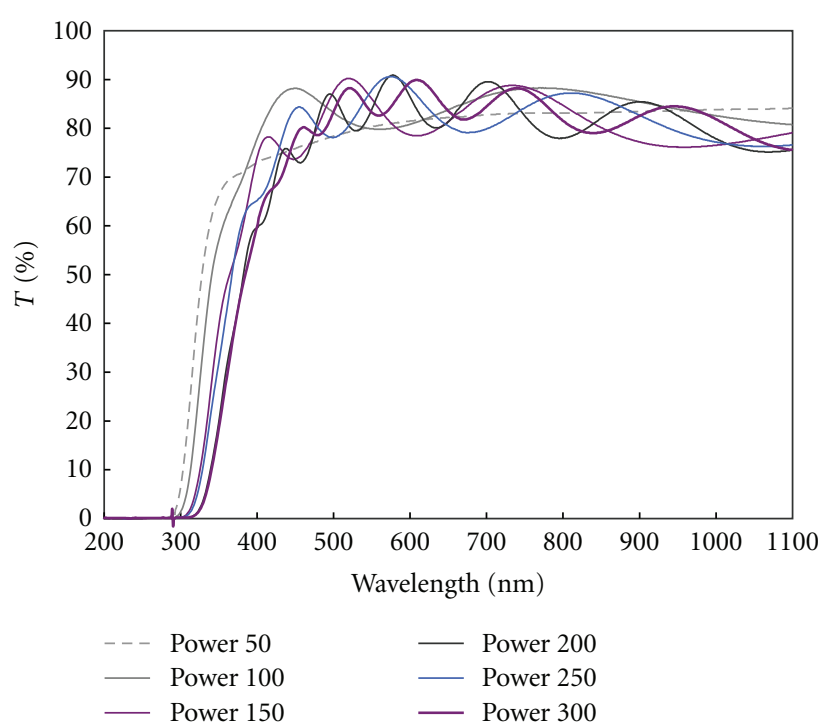

FIGURE 6: Optical transmittance for ITO thin films deposited for 40 min deposition time with various RF power.

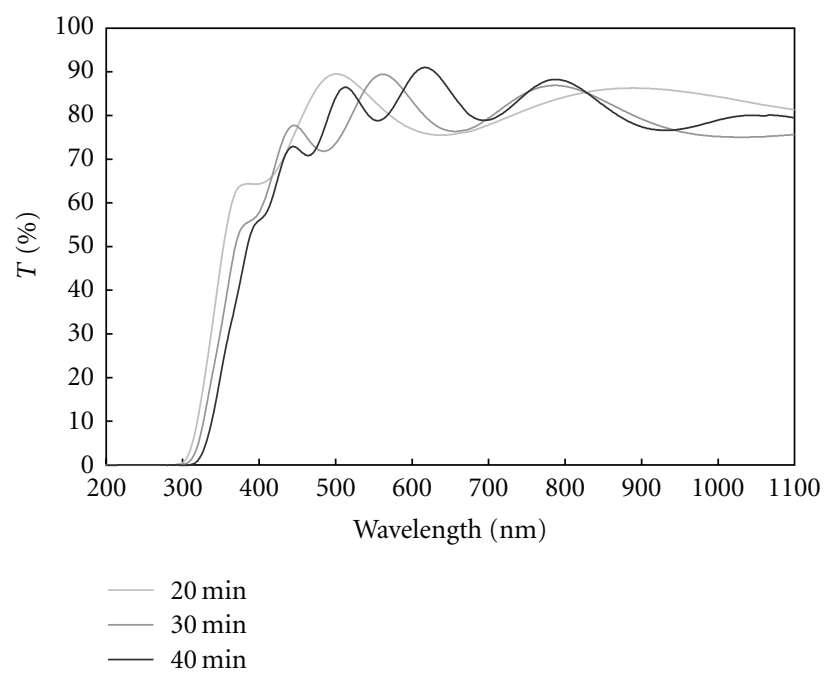

FIGURE 7: Optical transmittances for ITO thin films deposited using RF power value of $200 \mathrm{~W}$ and various deposition times.

thin films deposited as a function of RF deposition power and deposition time, respectively. From the results summarized in Figure 6 for various samples, it is observed that as the deposition power increases, the transmittance in the near infrared region decreases, which is explained by the increase of film's free electron absorption [4].

Also, the transmittance band edge is shifted to higher wavelengths as the RF power increases. Figure 7 shows the optical transmittance for the grown ITO thin films deposited at various deposition times. The optical transmission decreases as the ITO film thickness increases, which is attributed to the optical scattering arising from longer optical paths and also to the increased carrier concentration in the films $[25,27,28]$. The higher the carrier concentration value, the lower the ITO transmittance in the longer wavelength region. 
TABLE 2: Resistivity, thickness and refractive index of ITO thin films deposited using RF deposition power value of $200 \mathrm{~W}$ for various deposition times.

\begin{tabular}{lccc}
\hline $\begin{array}{l}\text { Deposition time } \\
(\mathrm{min})\end{array}$ & $\begin{array}{c}\text { Thickness } \\
(\mu \mathrm{m})\end{array}$ & $\begin{array}{c}\text { Refractive } \\
\text { index }\end{array}$ & $\begin{array}{c}\text { Resistivity } \\
(\Omega \cdot \mathrm{cm})\end{array}$ \\
\hline 10 & 0.46 & 1.499 & $5.18 \times 10^{-4}$ \\
20 & 0.52 & 1.501 & $4.1 \times 10^{-4}$ \\
30 & 0.63 & 1.503 & $1.92 \times 10^{-4}$ \\
40 & 1.09 & 1.506 & $1.62 \times 10^{-4}$ \\
\hline
\end{tabular}

Such higher free carrier density for thicker layers can be associated to the observed crystallite-size enhancement with increasing the film thickness that should reduce the number of donor sites trapped at the dislocations and grain boundaries [28].

3.4. Electrical Properties. Table 1 shows that the resistivity decreased from $77.15 \times 10^{-4} \Omega \cdot \mathrm{cm}$ at $50 \mathrm{~W}$ to reach its minimum value of $1.62 \times 10^{-4} \Omega \cdot \mathrm{cm}$ at $200 \mathrm{~W}$ then increased to $2.38 \times 10^{-4} \Omega \cdot \mathrm{cm}$ at $300 \mathrm{~W}$. Table 2 shows the resistivity of the ITO thin films deposited at a power of $200 \mathrm{~W}$ and various deposition times. At the deposition time of $10 \mathrm{~min}$, the transmittance value is $79 \%$ with a high resistivity of $5.18 \times 10^{-4} \Omega \cdot \mathrm{cm}$. At a high deposition time (40 min), the transmittance values increased to about $91 \%$, and the resistivity decreased to $1.62 \times 10^{-4} \Omega \cdot \mathrm{cm}$.

In the process of Ar sputtering (no oxygen), the oxygen concentration of the ITO film is lower than that of the target itself because a part of the oxygen sputtered from the target will not be incorporated into the film [17]. That is, the films without oxygen flow show metal-like characteristics with low transmittance, low resistivity, and higher oxygen vacancy concentration. On the other hand, as the power increases, the concentration of oxygen vacancies is drastically decreased resulting in a higher transmittance and resistivity like an oxide-insulating thin film $[33,34]$.

\section{Conclusions}

The ITO thin films are deposited by RF magnetron sputtering at room temperature. The film is in its amorphous state at low RF power. By increasing the deposition power and deposition time crystallization of the films was promoted because RF sputtering transfers the energy to the growing state by energetic bombardment and the activation energy for the crystallization of the film transferred during the deposition. To improve the electrical properties with low resistivity, ITO deposition should be processed under room temperature and low oxygen fraction. A tradeoff between low resistivity and high transmission exists due to the role that the oxygen vacancies have in the conduction and transmission. A higher number of oxygen vacancies facilitate conduction. The optical and electrical properties are strongly correlated to the preferred orientation of the films which is changed from (222) to (400) as the RF power increased (from $50 \mathrm{~W}$ to $300 \mathrm{~W}$ ), and the deposition time increased from 10 to $40 \mathrm{~min}$.
After heat treatment, the preferred orientation changed from (400) to (222) which is a result of the concentration of oxygen vacancy and the rearrangement of atoms in close-packed plane of $\mathrm{In}_{2} \mathrm{O}_{3}$ having a body-centered cubic structure.

\section{References}

[1] Z. Ding, C. An, Q. Li et al., "Preparation of ITO nanoparticles by liquid phase coprecipitation method," Journal of Nanomaterials, vol. 2010, Article ID 543601, 5 pages, 2010.

[2] Y. Hoshi and R. Ohki, "Low energy rf sputtering system for the deposition of ITO thin films," Electrochimica Acta, vol. 44, no. 21, pp. 3927-3932, 1999.

[3] C. Guillén and J. Herrero, "Structural, optical and electrical characteristics of ITO thin films deposited by sputtering on different polyester substrates," Materials Chemistry and Physics, vol. 112, no. 2, pp. 641-644, 2008.

[4] Y. Z. You, Y. S. Kim, D. H. Choi, H. S. Jang, J. H. Lee, and D. Kim, "Electrical and optical study of ITO films on glass and polymer substrates prepared by DC magnetron sputtering type negative metal ion beam deposition," Materials Chemistry and Physics, vol. 107, no. 2-3, pp. 444-448, 2008.

[5] H. Lei, K. Ichikawa, Y. Hoshi, M. Wang, T. Uchida, and Y. Sawada, "A study of deposition of ITO films on organic layer using facing target sputtering in Ar and $\mathrm{Kr}$ gases," Thin Solid Films, vol. 518, no. 11, pp. 2926-2929, 2010.

[6] C. J. Huang, Y. K. Su, and S. L. Wu, "The effect of solvent on the etching of ITO electrode," Materials Chemistry and Physics, vol. 84, no. 1, pp. 146-150, 2004.

[7] A. B. Kashyout, M. Soliman, M. El Gamal, and M. Fathy, "Preparation and characterization of nano particles $\mathrm{ZnO}$ films for dye-sensitized solar cells," Materials Chemistry and Physics, vol. 90, no. 2-3, pp. 230-233, 2005.

[8] A. B. Kashyout, M. Soliman, and M. Fathy, "Effect of preparation parameters on the properties of $\mathrm{TiO}_{2}$ nanoparticles for dye sensitized solar cells," Renewable Energy, vol. 35, no. 12, pp. 2914-2920, 2010.

[9] F. L. Wong, M. K. Fung, S. W. Tong, C. S. Lee, and S. T. Lee, "Flexible organic light-emitting device based on magnetron sputtered indium-tin-oxide on plastic substrate," Thin Solid Films, vol. 466, no. 1-2, pp. 225-230, 2004.

[10] N. Naghavi, A. Rougier, C. Marcel, C. Guéry, J. B. Leriche, and J. M. Tarascon, "Characterization of indium zinc oxide thin films prepared by pulsed laser deposition using a $\mathrm{Zn}_{3} \mathrm{I}_{2} \mathrm{O}_{6}$ target," Thin Solid Films, vol. 360, no. 1-2, pp. 233-240, 2000.

[11] H. Y. Yeom, N. Popovich, E. Chason, and D. C. Paine, "A study of the effect of process oxygen on stress evolution in d.c. magnetron-deposited tin-doped indium oxide," Thin Solid Films, vol. 411, no. 1, pp. 17-22, 2002.

[12] W. J. Lee, Y. K. Fang, J. J. Ho et al., "Optimizing indium tin oxide thin films with bipolar d.c.-pulsed magnetron sputtering for electrochromic device applications," Journal of Materials Science, vol. 13, no. 12, pp. 751-756, 2002.

[13] T. C. Gorjanc, D. Leong, C. Py, and D. Roth, "Room temperature deposition of ITO using r.f. magnetron sputtering," Thin Solid Films, vol. 413, no. 1-2, pp. 181-185, 2002.

[14] A. Kachouane, M. Addou, A. Bougrine et al., "Preparation and characterisation of tin-doped indium oxide films," Materials Chemistry and Physics, vol. 70, no. 3, pp. 285-289, 2001.

[15] G. H. Takaoka, D. Yamazaki, and J. Matsuo, "High quality ITO film formation by the simultaneous use of cluster ion beam and laser irradiation," Materials Chemistry and Physics, vol. 74, no. 1, pp. 104-108, 2002. 
[16] M. J. Alam and D. C. Cameron, "Investigation of annealing effects on sol-gel deposited indium tin oxide thin films in different atmospheres," Thin Solid Films, vol. 420-421, pp. 7682, 2002.

[17] J. Vetrone and Y. W. Chung, "Organo-metallic chemical vapor deposition of tin oxide single crystal and polycrystalline films," Journal of Vacuum Science and Technology A, vol. 9, no. 6, pp. 3041-3047, 1991.

[18] D. Yu, W. Yu, D. Wang, and Y. Qian, "Structural, optical, and electrical properties of indium tin oxide films with corundum structure fabricated by a sol-gel route based on solvothermal reactions," Thin Solid Films, vol. 419, no. 1-2, pp. 166-172, 2002.

[19] S. H. Keshmiri, M. R. Roknabadi, and S. Ashok, "A novel technique for increasing electron mobility of indium-tin-oxide transparent conducting films," Thin Solid Films, vol. 413, no. 1-2, pp. 167-170, 2002.

[20] C. H. Yang, S. C. Lee, T. C. Lin, and S. C. Chen, "Electrical and optical properties of indium tin oxide films prepared on plastic substrates by radio frequency magnetron sputtering," Thin Solid Films, vol. 516, no. 8, pp. 1984-1991, 2008.

[21] H. Morikawa and M. Fujita, "Crystallization and electrical property change on the annealing of amorphous indiumoxide and indium-tin-oxide thin films," Thin Solid Films, vol. 359, no. 1, pp. 61-67, 2000.

[22] M. Kamei, H. Enomoto, and I. Yasui, "Origin of the crystalline orientation dependence of the electrical properties in tindoped indium oxide films," Thin Solid Films, vol. 392, no. 2, pp. 265-268, 2001.

[23] R. Balasundaraprabhu, E. V. Monakhov, N. Muthukumarasamy, O. Nilsen, and B. G. Svensson, "Effect of heat treatment on ITO film properties and ITO/p-Si interface," Materials Chemistry and Physics, vol. 114, no. 1, pp. 425-429, 2009.

[24] B.D. Cullity, Elements of X-Ray Diffraction, Addison-Wesley Publishing Company, Boston, Mass, USA, 2nd edition, 1978.

[25] S.-I. Jun, T. E. McKnight, M. L. Simpson, and P. D. Rack, "A statistical parameter study of indium tin oxide thin films deposited by radio-frequency sputtering," Thin Solid Films, vol. 476, no. 1, pp. 59-64, 2005.

[26] S. Seki, Y. Sawada, and T. Nishide, "Indium-tin-oxide thin films prepared by dip-coating of indium diacetate monohydroxide and tin dichloride," Thin Solid Films, vol. 388, no. 1-2, pp. 22-26, 2001.

[27] C. Guillén and J. Herrero, "Polycrystalline growth and recrystallization processes in sputtered ITO thin films," Thin Solid Films, vol. 510, no. 1-2, pp. 260-264, 2006.

[28] H. Kim, J. S. Horwitz, G. Kushto et al., "Effect of film thickness on the properties of indium tin oxide thin films," Journal of Applied Physics, vol. 88, no. 10, pp. 6021-6025, 2000.

[29] G. Korotcenkov, V. Brinzari, A. Cerneavschi et al., "The influence of film structure on $\mathrm{In}_{2} \mathrm{O}_{3}$ gas response," Thin Solid Films, vol. 460, no. 1-2, pp. 315-323, 2004.

[30] Z. Qiao, R. Latz, and D. Mergel, "Thickness dependence of $\mathrm{In}_{2} \mathrm{O}_{3}$ : Sn film growth," Thin Solid Films, vol. 466, no. 1-2, pp. 250-258, 2004.

[31] H.-N. Cui, V. Teixeira, and A. Monteiro, "Microstructure study of indium tin oxide thin films by optical methods," Vacuum, vol. 67, no. 3-4, pp. 589-594, 2002.

[32] J. C. Manifacier, J. Gasiot, and J. P. Fillard, "A simple method for the determination of the optical constants $n, k$ and the thickness of a weakly absorbing thin film," Journal of Physics E, vol. 9, no. 11, pp. 1002-1004, 1976.

[33] I. Baía, B. Fernandes, P. Nunes, M. Quintela, and R. Martins, "Influence of the process parameters on structural and electrical properties of r.f. magnetron sputtering ITO films," Thin Solid Films, vol. 383, no. 1-2, pp. 244-247, 2001.

[34] C. G. Choi, K. No, W. J. Lee et al., "Effects of oxygen partial pressure on the microstructure and electrical properties of indium tin oxide film prepared by d.c. magnetron sputtering," Thin Solid Films, vol. 258, no. 1-2, pp. 274-278, 1995. 


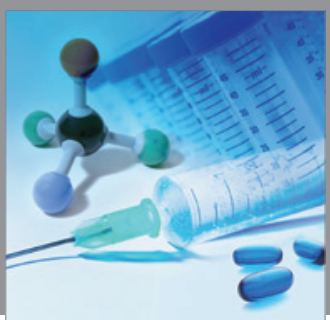

International Journal of

Medicinal Chemistry

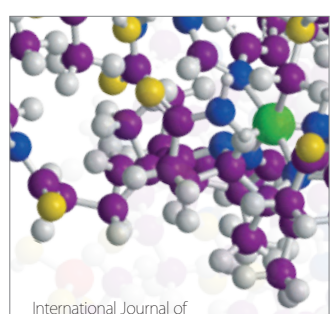

Carbohydrate Chemistry

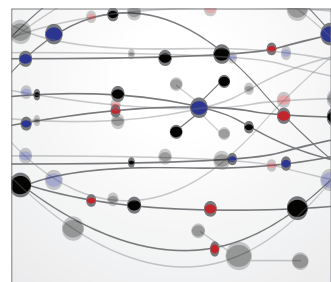

The Scientific World Journal
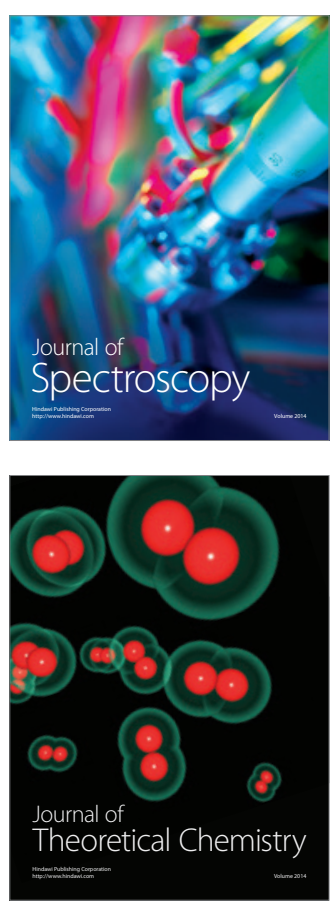
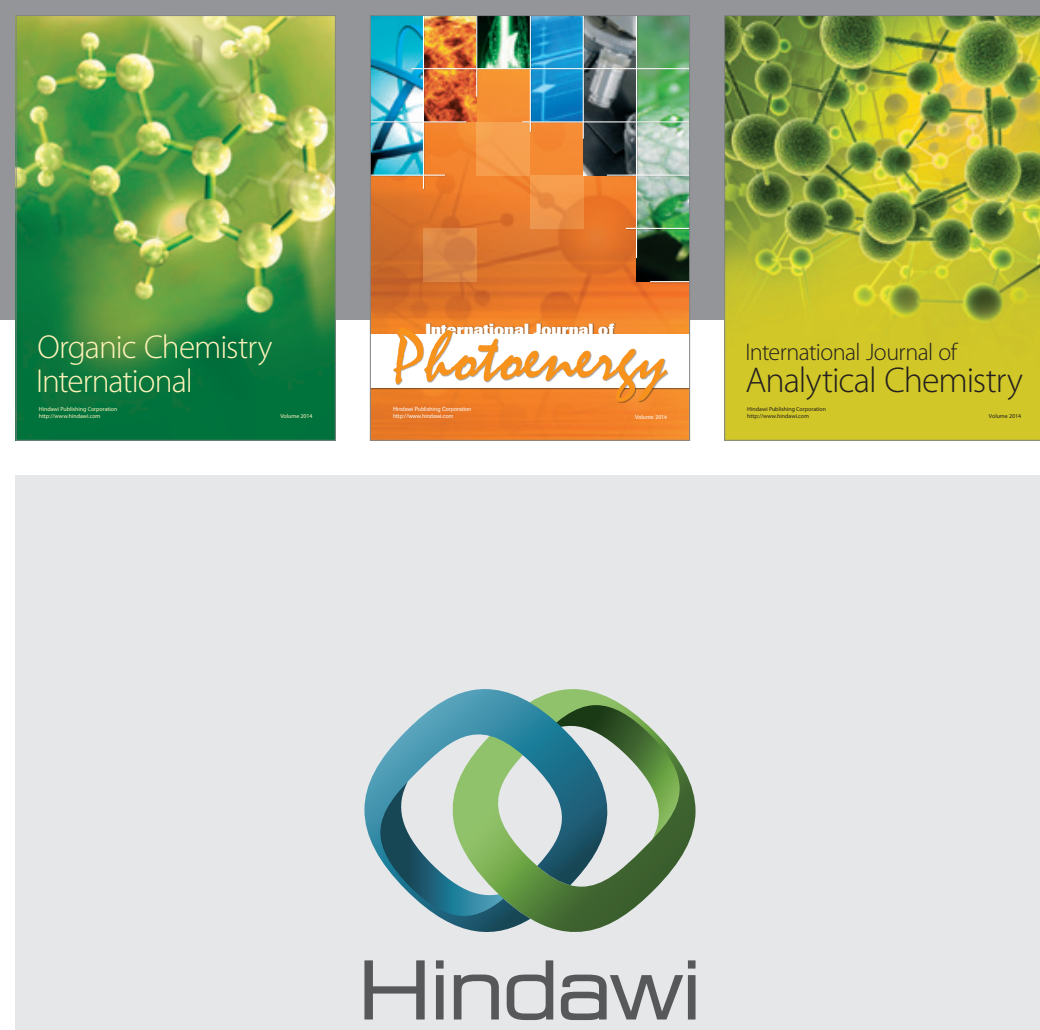

Submit your manuscripts at

http://www.hindawi.com
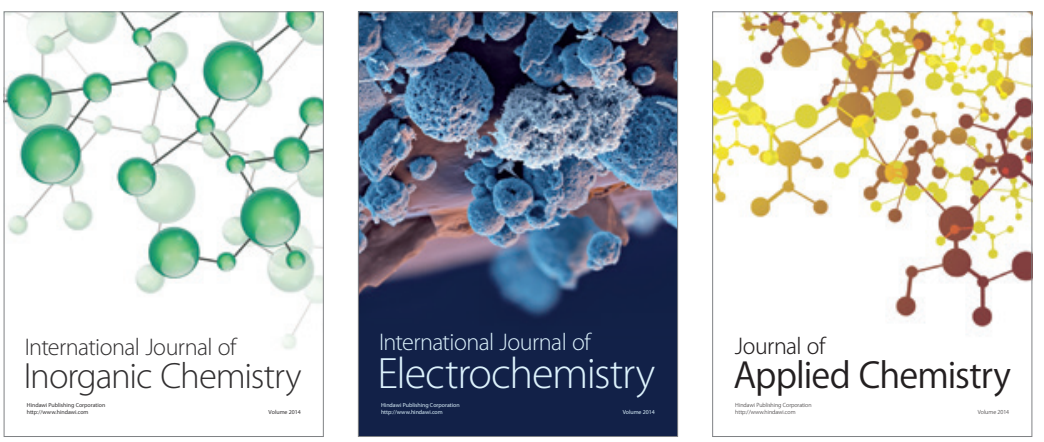

Journal of

Applied Chemistry
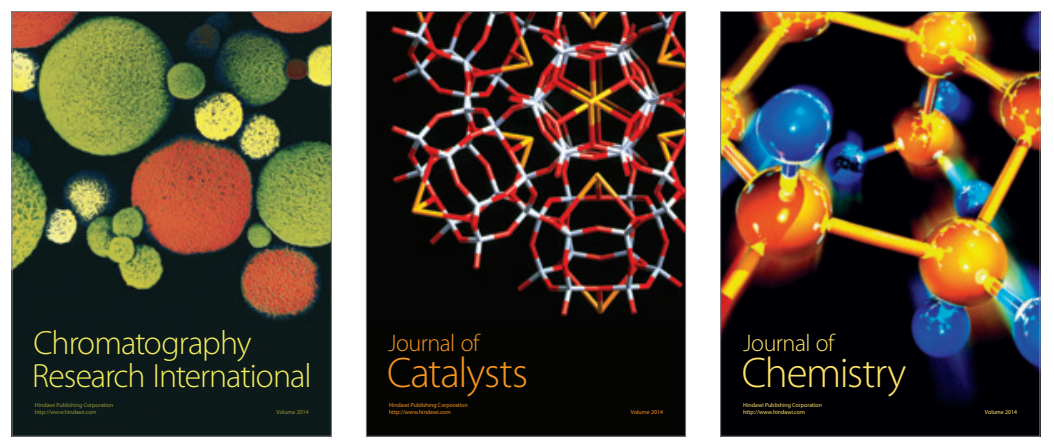
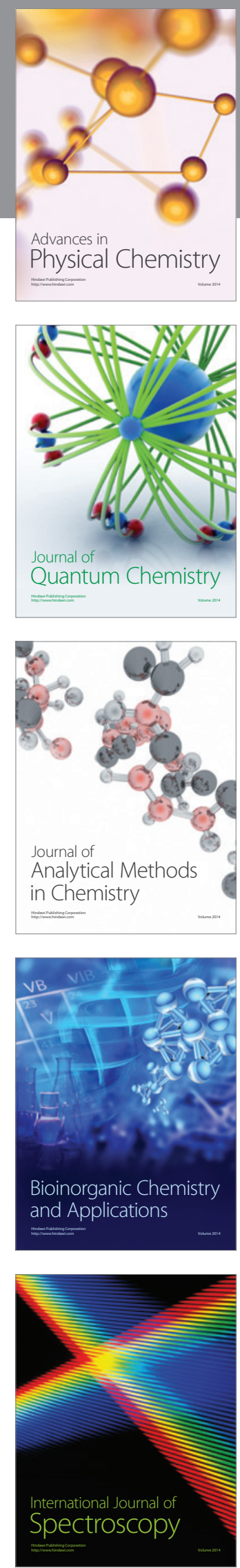